\title{
Value Proposition in Mobile Government
}

\author{
Chien-Chih $\mathrm{Yu}$ \\ Dept. of MIS, National ChengChi University, Taipei, Taiwan \\ ccyu@mis.nccu.edu.tw
}

\begin{abstract}
This paper aims at providing an integrated framework and process for identifying and assessing values in mobile government applications. Value proposition with related management issues of offering and delivering mobile government services to citizens, businesses, and government agencies are described and discussed. Based on a business model perspective, we further specify and structurally link constituents, values, services, and indicators for mobile government systems. The proposed approach and results could be valuable for adoption to guide the planning and evaluation of value-centric mobile government strategies and projects.
\end{abstract}

Keywords: Value proposition, mobile government, mobile services, business model.

\section{Introduction}

Electronic government (e-government, EG) aims at delivering public services to citizens and businesses, leveraging internal productivities of government agencies, and integrating service systems across government organizations by adopting and using information and communication technologies (ICTs) in innovative ways. Mobile government (m-government, MG), with the adoption of mobile technologies, refers to a functional extension of e-government that enables citizens, businesses, and government employees to access government information and services via mobile devices [24]. While ubiquitous government (u-government, UG) emphasizes on the new form of interactions and transactions that are possibly operated anywhere, at any time, and on various devices and networks due to the utilization of ubiquitous technologies [3]. The same as for e-government, proposing values to all stakeholders including citizens, businesses, and government agencies have been regarded as a key success factor for promoting the development and use of mobile and ubiquitous government services. Therefore, value proposition and value creation are considered as major objectives and central tasks for the deployment and management of MG/UG related strategies and systems. For simplicity, we use m-government to cover both MG and UG characteristics in the subsequent discussions. On the other hand, business models (BMs) have been noted as proper means to illustrate the concepts and methods for value proposition in both e-business and e-government domains [7,13,18,23,28]. In general, business models focus on specifying structural components and 
relationships such as actors, services, value, activities, and communications for directing business operations. Therefore, to design and develop suitable EG business model is a key to facilitate value proposition and sustain continuous operations of EG services. Likewise, designing and operating mobile-characterized business models are critical to the success in promoting the provision and usage of MG services, as well as in achieving the goals of proposing and creating public value. In the literature, the emerging issues regarding value proposition and business modeling for e-government and $\mathrm{m}$-government have increasingly attracted research attentions in the past few years. Yet, a unified view and an integrated framework towards illustrating the concepts and methodologies for value proposition and business modeling are still lacking. As a result, the demand of a comprehensive study in this field is significant and strong.

In the literature of e-government applications, various research attempts have proposed some views for identifying value. For instance, identified EG related value include citizen value, business value, employee value, organization value, service chain value, administration value, society value and nation value [28]. While focusing on the mobile commerce domain, among very limited research works, one approach of value proposition characterizes business value into three major themes including ubiquitous access, productivity enabler, and positive image [10]. Overall proposed value includes instant access, emergency use, enhanced anytime access to new services, and increased productivity. When targeting on the m-government domain, the shortfall of research works dealing with value proposition issues are even more severe. Research literature in this area is very limited and lacks of in-depth investigations. Therefore, the goal of this paper is to propose an integrated conceptual framework for identifying and proposing value to fit the m-government applications. Value proposition with related management issues for providing and delivering mobile public services to citizens, businesses, and government agencies are to be described and discussed. Based on an adaptable EG/MG business model perspective, value, constituents, services, and indicators for MG systems are specified and structurally presented. The proposed value-centric BM framework can then be used to support the planning and evaluation of MG related strategies and systems. The rest of this paper is organized as follows. In section 2, a brief literature review on MG related value is provided. In section 3, an integrated framework is presented with specified value dimensions and elements. In section 4, MG related value, constituents, services, and indicators are illustrated based on a value-centric BM perspective. Concluding remarks and discussions are provided in the final section.

\section{$2 \quad$ Literature Review}

Since previous works focused on value proposition for mobile government are very limited, brief reviews of the research literature regarding value proposition in ebusiness and e-government, as well as in m-commerce and m-government domains are provided in this section to show the current research status and critical issues. 


\subsection{Value Proposition in E-Business and E-Government}

Value, in general, refers to benefits or simply convenience a technology or service affords the end user, and value proposition is an equation of the all positive factors that interest the individual [20]. Value proposition identifies how the supplier fulfills the customer's needs across different consumer roles, and further specifies the interdependence between the performance attributes of products or services and the fulfillment of needs [6].

In the e-business domain, issues of value proposition and creation have been discussed from various business perspectives including enterprise, customer, supply chain, and markets. Value types identified by previous works include business value, customer value, product value, service value, relationship value, supply chain value, etc. Value assessment is carried out by using a set of financial and non-monetary measures. For instances, commonly mentioned value in the e-business literature include profit gains, cost savings, brand awareness, customer loyalty, etc for business companies, and time efficiency, location convenience, price deduction, customization and personalization, security and privacy protection, etc for customers.

In the e-government literature, although creating value for citizens, government agencies organizational institutions, and other stakeholders has been considered critical to the success of EG strategies and initiatives, there are only very few works comprehensively addressing value proposition, creation and assessment issues $[4,11,14,18]$. Among the works for developing value related framework, Grimsley and Meehan (2007) propose an evaluative design framework for EG information system projects in which well-informedness, personal control, and influence are adopted as evaluative measures for public satisfaction and trust [9]. Yu (2008) presents a value-centric EG service framework that encompasses four balanced scorecard (BSC) based dimensions for managing respectively citizen and business value, government employee and organization value, service chain, institution and administration value, as well as society and nation value [28]. Badri and Alshare (2008) present an EG business value model that comprises six dimensions including IT capability, search and transaction-oriented uses of EG, intelligence generation, new business development, time savings, and firm profitability [4]. Prakash, Jaiswal, and Gulla (2009) suggest using a conceptual framework with three key dimensions including constituent service, productivity, and political consideration for assessing public value in terms of dimension associated value indicators [19]. Hossain et al (2011), through investigating the impact of organizational assimilation of EG systems on business value creation, operationalize the measure of EG system value in three dimensions including organizational efficiency, operational transparency, and public satisfaction [11]. Panagiotopoulos et al (2012), for analyzing and evaluating ICTs in public engagement, apply a business model perspective that consists of four dimensions including value proposition (effects), value network (actors), value architecture (resources), and value finance (costs) [18]. The value proposition is to describe the decision stages, activities, and tools, the intended benefits and effects, as well as the audience engagement. 
It can be seen that since issues of value identification, proposition, assessment, and creation regarding e-business and e-government applications are largely unexplored and no consensus exists in views and structures about value, more research efforts in the direction of developing framework and metrics for defining and depicting value in both the e-business and e-government domains are strongly demanded.

\subsection{Value Proposition in M-Commerce and M-Government}

Mobile services refer to information, communication, and transaction services that are accessed and delivered via mobile communications networks. Mobile services are often classified into different categories by using different perspectives. For instances, $\mathrm{m}$-services can be categorized into m-communications services, m-information services, m-transaction services, m-entertainment services, and m-community services etc by service types, into m-commerce services, and m-government services by service sectors and environments, or into m-tourism services, m-healthcare services, m-learning services, m-auction services, m-agriculture services, memergency services, and mobile law enforcement services etc by application domains $[1,2,35,6,12,15,16,17,21,22,24,25,26]$. Specific characteristics and features of $\mathrm{m}$ services often mentioned include mobility, convenience, portability, adaptivity, ubiquity, personalization, localization, broadcasting, and security etc. Players involved in the mobile service chain include mobile service providers, mobile content providers, service and content aggregators, mobile device providers, mobile gateway and interface providers, and mobile network operators, etc. As mobile devices become more powerful and affordable, and more mobile services and apps are available and accessible, the goal of proposing and creating value for mobile applications becomes more achievable. In the literature, there are a plenty of previous works addressing applications and impacts of m-services in both the business and government sectors. However, there are still very few research efforts sufficiently examining the structure and process of value proposition in the mobile application domain. The lack of a unified view for value proposition of mobile services and systems is also significant.

Among research works related to mobile commerce value, Clarke III (2001) considers value proposition as a means to engender a productive m-commerce strategy, and specifies four dimensions including ubiquity, convenience, localization, and personalization to gain advantages [6]. By defining value proposition of mobile applications as the net value of the benefits and costs associated with the adoption and adaptation of mobile applications, Nah, Siau, and Sheng (2005) adopt a value-focused thinking approach to build a means-ends objective network that depicts the causal relationships among value-converted fundamental and means objectives. Six most important fundamental objectives identified are efficiency, effectiveness, customer satisfaction, security, cost, and employee acceptance [16]. Through investigating industrial experts' perception of characteristics and value for mobile information systems, Hoehle and Scornavacca (2008) identify three major themes for value proposition including ubiquitous access, productivity enabler, and positive image [10]. Emphasizing that value proposition to customers and the balance between 
privacy, value, and control are keys to the acceptance of mobile technologies and services, Renegar, Michael, and Michael (2008) identify convenience, location-based services, time saving, better tracking, cost reduction, security enhancement, as well as lower prices and special promotions as the m-business value [20]. Focusing on defining m-commerce services and business models, Varshney (2008) described overall value proposed to mobile customers in terms of instant access, emergency use, enhanced anytime access to new services, and increased productivity. He also points out that required functions for facilitating $\mathrm{m}$-commerce services are location management, real-time delivery or service quality, transaction support, security, and wireless network reliability [25]. Focusing on the improvement of user-centric mcommerce services effectiveness, Germanakos et al. (2008) identify personalization, localization and immediacy as three dimensions for the mobile marketplace that provides services including text-based short message services (SMS), multimedia message services (MMS), and location-based services (LBS) [8].

As for value related works in the mobile government literature, Anttiroiko (2005) argues that the ultimate goal of introducing u-government is to generate added value from the point of view of individuals and society as a whole [3]. He considers value as benefits related to the overall performance of public administration, such as increased productivity and effectiveness, smooth internal operations and inter-organizational interactions, better service delivery, and multiple channels for interaction. He also classifies public u-services with added value into a variety of application areas including travel and transportation, public service directories, registrations and permits, access and support, etc. Trimi and Sheng (2008), based on reviewing MG initiatives in several leading countries, consider MG as value-added EG with advantages in various aspects [24]. These advantages include improving the delivery of government information and services, providing best solutions to Internet connectivity problems and digital divide issues, offering a more cost-effective choice for national networking, helping to avoid problems of corruption and low productivity, as well as increasing government employees' efficiency and effectiveness. Most MG applications implemented are in the segments of G2C (government to citizen) and IEE (internal efficiency and effectiveness). For example, m-G2C services include government information access, text message alerts, GPS-based traffic guides, mobile tax and fee payments, and electronic ID card. M-IEE services include internal communications, in-vehicle access to crime databases for police officers, on-the-spot information processing for field inspections, tracking task assignments to workers, parking/traffic monitoring, and tax management. Ntalinai, Costopoulou, and Karetsos (2008) present a framework for introducing agricultural mobile G2B (government to business) services [17]. The generic agricultural $\mathrm{m}-\mathrm{G} 2 \mathrm{~B}$ information and interaction services include news and policy, notification and alerts, forecasts and consulting, petitions and financial transactions, search engine and employment market, polls and forums, etc. The benefits for using the MG services are mobility and ubiquity, provision of location-based government services, time saving, on-time information delivery, ease of use, and improving emergency management. For addressing the acceptance issues of $\mathrm{MG}$ services, Aloudat and Michael (2011) [2], and Hu et al (2011) [12], focus in emergency and law enforcement applications respectively. Factors considered in the former study 
include trust, perceived risk, perceived usefulness, perceived ease of use, visibility, perceived service quality, perceived currency, perceived accuracy, perceived responsiveness, privacy concerns, data collection concerns, and the concern of unauthorized use, while in the latter study, factors tested include efficiency gain, timely assistance, social influence, perceived usefulness, perceived ease of use, and facilitating conditions. Yan, Zhang, and Zhang (2012), provide a value analysis framework with three stages including characteristics, innovation and changes, and value for illustrating the path of MG value generation [27]. Value identified include narrow digital divide, reduce management granularity, instant response, custom personal service, initiative delivery, on-spot management and service, low cost, and high efficiency. Berg et al (2013), targeting on cellular citizenship, report the usage of GPS-enabled smartphones as nation-wide real-time data collection mechanisms in developing countries [5]. The system is developed to support policy makers and planners of both the local and national levels in monitoring, assessing, and arranging human and material resources. The goal is to enhance government accountability by improving transparency in decision making and resource allocation, while increasing local planning capacity and ownership.

By reviewing research issues regarding value proposition, we summarize that previous research works address EG/MG value only partially and with inconsistent views. There is neither unified view nor complete and commonly accepted conceptual framework for illustrating the integrated structure of value proposition. It can also be noted that value proposition is a central strategic task and critical success factor in the planning and implementation of EG/MG services, value proposed to EG/MG stakeholders should be included as core elements of business models, and value associated metrics and indicators is the basis of EG/MG performance measurement. Since research in the literature addressing $\mathrm{MG}$ value proposition is still in its initial stage, more comprehensive studies and in-depth discussions are needed.

\section{Integrated Framework for MG Value Proposition}

To be specific, value can be considered as tangible and intangible benefits of products and/or services perceived by and exchanged between stakeholders. Then, value proposition is to propose a set of value to specific stakeholders with an implicit or explicit promise that the proposed value is to be created for and delivered to them. Many researchers consider MG as value-added EG with advantages and benefits to individuals, governments, and society $[3,24]$. Therefore, for better understanding value proposition issues of MG services and systems, characteristics of the added value to MG services, types of delivered MG services that create value, and constituents who provide and/or use MG services to gain benefits must be realized. By doing content analysis from previous studies, as well as taking into account value chain management and business modeling concepts and methodologies, we develop an integrated framework with three dimensions including functional features, user acceptance, and user benefits, for classifying MG related value. User benefits are further classified into four constituent categories, namely, public beneficiaries, 
government officers and employees, participating parties of the government service chain, as well as society and nation as a whole. Figure 1 depicts the conceptual framework for value proposition in mobile government. Value dimensions and associated elements are described in the following sub-sections.

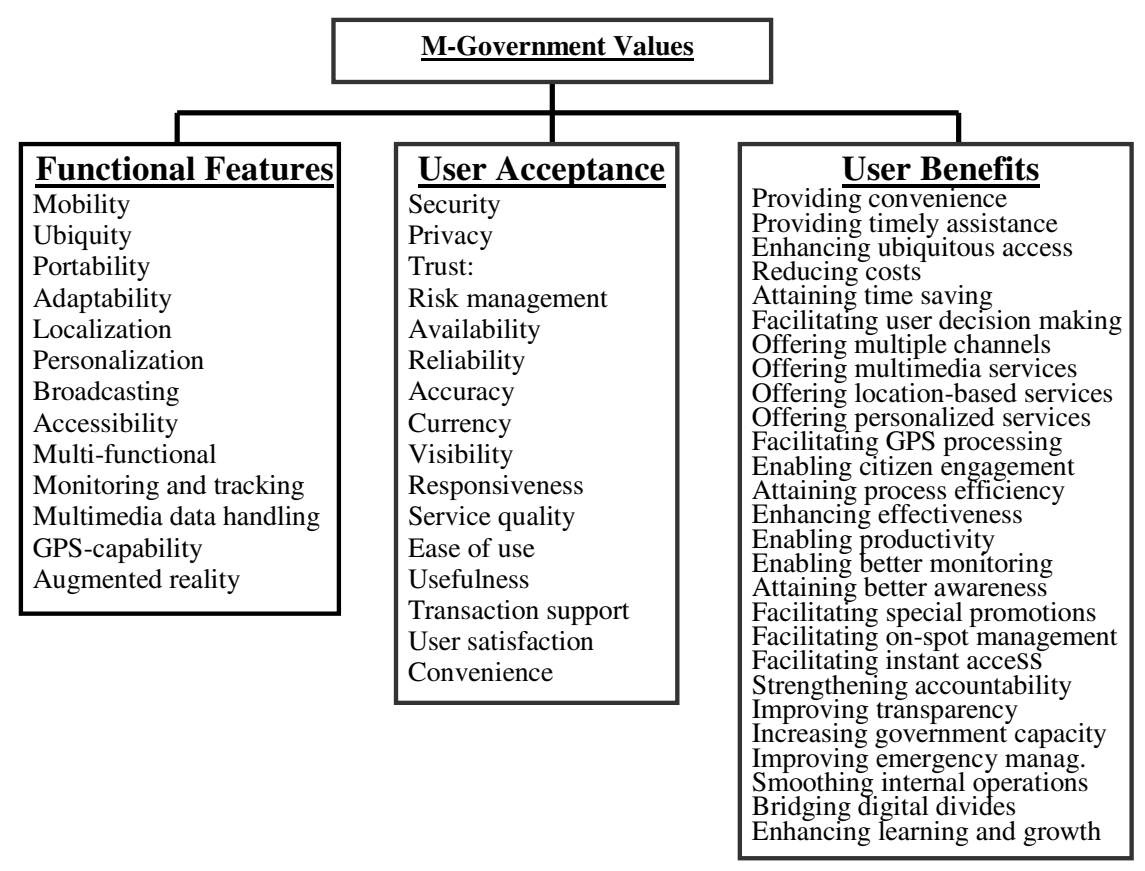

Fig. 1. Conceptual framework for MG value proposition

\subsection{Functional Features of MG Services}

Functional features of MG services refer to the characteristics of enhanced and enabled functions that reveal added values of the m-government services. These MG functional features include mobility [17], ubiquity [6,10,17,24,25], portability [10], adaptability [19], personalization $[6,8,10]$, localization/location management $[6,8,17,20,25]$, broadcasting, accessibility $[8,10,24,25]$, multi-functional $[5,10]$, monitoring and tracking [20,24], multimedia data handling [8], GPS-capability [5], and augmented reality (http://mobilegovwiki.howto.gov/Augmented+Reality).

Mobility: Users can get access to mobile services independent of location and time by using mobile devices.

Ubiquity: Mobile services are available $24 \times 7$ and can be accessed at anytime and anywhere with multi-channel connections.

Portability: Mobile devices are easy to be carried around and can always be connected for accessing mobile services via any mobile communications networks. 
Adaptability: Mobile services and applications can be adapted to users' environment such as device types, network bandwidth, and locations.

Localization: The capability to locate mobile users at any particular moment and to offer location-based information and services.

Personalization: Mobile services and applications are tailored to meet users' needs, preferences, conditions, and environments.

Broadcasting: Information can be delivered simultaneously to all mobile users within a specific geographical region.

Accessibility: Anyone can easily access government information and services with the mobile devices.

Multi-functional: Many different functions such as search, communication, community, multimedia data processing etc are integrated in the mobile devices.

Monitoring and tracking: Data and entities can be monitored and tracked for controlling status changes.

Multimedia data handling: Text, image, audio and video data can be handled using the same mobile device.

GPS-capability: Geo-referred data can be collected and presented.

Augmented reality: Multimedia information about the environment and its objects can be overlaid on the real world.

\subsection{User Acceptance Levels of MG Services}

User acceptance levels of MG services refer to the user perceived value of the $\mathrm{m}$ government services and technology that reinforce their intention to use. These factors include security enhancement [2,10,16,20,25], user satisfaction [16], privacy protection [2,20], service quality [2,25], transaction support [12,25], system reliability. [25], ease of use [12,17], usefulness [2,12], trust [2], risk management [2], visibility [2], currency [2], accuracy [2[, and responsiveness [2,27].

Security: The ability to ensure data and system integrity, as well as to prevent, detect, and control security attacks such as repudiation and intrusion in MG environments.

Privacy: The ability to ensure that access to user accounts is restricted to authorized individuals and that the private user information is protected from unauthorized use.

Trust: The ability to ensure that mobile users are well-informed, information is accurate, transactions are secure, and systems are reliable.

Risk management: The ability to handle analysis, prevention, and recovery tasks regarding risk events in the $\mathrm{MG}$ environment.

Availability: The ability to ensure that information, information accessing channels, $\mathrm{m}$-service functions and systems are available when requested.

Reliability: The ability to ensure that mobile services, systems as well as outcomes are consistent and accurate, and are dependably and continuously operated.

Accuracy: The ability to ensure that data and information are accurate.

Currency: The ability to maintain the up-to-date data and ensure timely information. 
Visibility: The ability to make the mobile service process visible to the users.

Responsiveness: The ability to quickly respond to user requests and transactions.

Service quality: The ability to assure high quality of delivered m-services.

Ease of use: The easiness in accessing and using m-services with the provision of friendly user interfaces and mechanisms.

Usefulness: The m-services are perceived useful to the users.

Transaction support: The ability to support users in conducting mobile transactions.

User satisfaction: The ability to satisfy users with proper information and services.

Convenience: Mobile services can be accessed by users anytime and anywhere.

\subsection{User Benefits of MG Services}

User benefits of MG services refer to value as benefits that are to be created and delivered to users. Based on the functional features and technological capabilities of the MG services, user benefits to various constituent groups include the followings.

Providing convenience in using the m-government services and systems [6,20].

Providing timely assistance and transaction support to users [12].

Enhancing ubiquitous access to information and services [10,24,25].

Reducing costs in developing, operating, and using m-government services [16,20,24].

Attaining time saving in the m-government services process $[17,20]$.

Facilitating user decision making process and enhancing effectiveness [24].

Offering multiple channels for two-way user-government interactions [3].

Offering more multimedia services for m-government users [8].

Offering more location-based services for m-government users [8,17,20,27].

Offering more personalized services for m-government users [6,8,10,27].

Facilitating GPS-enabled data and maps processing [5,24].

Enabling citizen engagement and increasing social influence [12].

Attaining high process efficiency in accessing and delivering m-government services $[3,12,16,17,24,27]$.

Enhancing management effectiveness for local and central governments [3,8,16,24,27].

Enabling productivity in different sectors and levels of government agencies [3,10,24,25].

Enabling better monitoring, tracking, and control of data management and services delivery processes $[5,20,24]$.

Attaining better awareness and positive image for government [10].

Facilitating special promotions of government activities [20].

Facilitating on-spot and location management of data and events [25,27].

Facilitating instant and/or real-time data collection, information access, service delivery, and transaction response [5,8,17,24,25,27].

Strengthening government accountability and reducing management granularity [5,27].

Improving transparency in service delivery and decision making [5].

Increasing local government capacity in planning, operation, and control [5].

Improving emergency use and management of government resources [17,25].

Smoothing internal operations and inter-organizational interactions [3]. 
Bridging/Narrowing domestic and international digital divides [24,27].

Enhancing equal digital opportunities and nation wide learning and growth [28].

\section{Business Model Perspective for MG Value Proposition}

In this section, value proposed to m-government users as benefits are to be classified into four constituent groups based on a business model perspective. With the BM perspective, services, constituents, value, strategic objectives, and performance indicators related to MG systems can be structurally linked and presented. By adapting a value-centric business model with the balanced scorecard perspectives provided by $\mathrm{Yu}$ (2008), the four BSC-BM perspectives for MG include public beneficiaries, government internal organization and process, government service chain, as well as society and nation [28]. In the public beneficiaries perspective, the constituents include citizens, businesses, and NGOs, the value types include citizen value, business value, and NGO value, the value elements are constituent specific benefits derived from previous sections. Strategic objectives of MG services for this group are specified goals transformed from the value elements (i.e. constituent benefits) associated with this constituent group. The valueadded MG services are provided in the $\mathrm{m}-\mathrm{G} 2 \mathrm{C}$ and $\mathrm{m}-\mathrm{G} 2 \mathrm{~B}$ systems. The value indicators for performance measurement can then be specified accordingly. The constituent groups and associated value of the other three value-centric BSC-BM perspectives include the government officers and employees with employee value and organization value in the government internal organization and process perspective, the participating parties of the government service chain with service chain value for the entire chain and all participating parties in the government service chain perspective, as well as the society and nation as a whole with society value and nation value in the society and nation perspective. Figure 2 illustrates the BSC-BM based MG value proposition model.

\begin{tabular}{|c|c|c|}
\hline \multirow{2}{*}{\begin{tabular}{l}
\multicolumn{1}{c|}{ Public Beneficiaries } \\
Perspective \\
Value: \\
Busitizen value, \\
Users: Citizens/Businesses \\
Systems: mG2C, mG2B \\
Services: Information, \\
Taxation, Registration, etc. \\
Performances: \\
Services accessibility, \\
Levels of satisfaction, \\
personalization, \\
participation, etc.
\end{tabular}} & \multicolumn{2}{|c|}{$\begin{array}{l}\text { Government Service Chain Perspective } \\
\text { Value: SC value, Intitution value, Administration value } \\
\text { Users: Government agencies within and across functional depts } \\
\text { Systems: mG2G-HI, mG2G-VI } \\
\text { Services: Document interchange, DB integration, etc. } \\
\text { Performances: Levels of services integration, time reduction, etc. }\end{array}$} \\
\hline & vices & $\begin{array}{l}\text { Gov. Internal Org. and } \\
\text { Proc. Perspective } \\
\text { Value: Employee value, } \\
\text { Organization value } \\
\text { Users: Employees, Staffs } \\
\text { Systems: mG2E, mIEE }\end{array}$ \\
\hline \multicolumn{2}{|c|}{ Society and Nation Perspective } & $\begin{array}{l}\text { security control, etc. } \\
\text { Performances: } \\
\text { Levels of employee satis- } \\
\text { faction, } \\
\text { organizational capability, } \\
\text { cost saving, etc. }\end{array}$ \\
\hline
\end{tabular}

Fig. 2. Value proposition model based on BSC-BM perspectives 
Example m-G2C services include (1) mobile information services for accessing government information about news, weather, traffic, tourism, healthcare, and jobs, (2) mobile notification and alert services for sending text message alerts and reminders about emergency conditions, tax payments, and others, (3) mobile transaction services for conducting tax and fee payments, (4) location-based services for accessing GPS-enabled tour guides and road maps, (5) mobile community services for connecting people and authorities, as well as sharing knowledge and real-time information, (6) other m-services such as personalized, collaborative, and participative services.

\section{Concluding Remarks and Discussions}

In this paper, we propose an integrated framework with three dimensions including functional features, user acceptance, and user benefits for value proposition in $\mathrm{m}$ government. We then use BSC based business model perspectives to classify user benefits into four constituent categories, namely, public beneficiaries, government officers and employees, participating parties of the government service chain, as well as society and nation as a whole. Value, users, systems, services, and performance indicators for each group are structurally presented. The contribution and implications of this paper are twofold. By using the proposed value framework and business model, MG planners can firstly select proper value elements from three dimensions to effectively enable m-services functions, assure user acceptance, and generate user benefits, and can secondly develop and implement MG related strategies and action plans, as well as evaluate corresponding performances based on the four BSC-BM perspectives. Furthermore, the framework is rather complete and flexible to cover previous and support future cases of MG value proposition. Directions of future research include validating the proposed $\mathrm{MG}$ value framework and associated indicators by conducting interviews, focus group discussions, and case studies, as well as adopting the value-centric BSC-BM for real case operation and evaluation.

\section{References}

1. Alhomod, S.M., Shafi, M.M.: Mobile Phone and e-Government: The Future for Dissemination of Public Services. Universal Access in the Information Society (published online: September 30, 2012)

2. Aloudat, A., Michael, K.: Towards the Regulation of Ubiquitous Mobile Government: A Case Studey on Location-Based Emergency Services in Australia. Electronic Commerce Research 11(1), 31-74 (2011)

3. Anttiroiko, A.: Towards Ubiquitous Government: The Case of Finland. E-Service Journal 4(1), 65-99 (2005)

4. Badri, M.A., Alshare, K.: A Path Analytic Model and Measurement of the Business Value of e-Government: An International Perspective. International Journal of Information Management 28(6), 524-535 (2008)

5. Berg, M., Pokharel, P., Sweetland, A., Modi, V.: Cellular Citizenship: Invigorating Development Through Mobile. Harvard International Review 34(3), 28-32 (2013) 
6. Clarke III, I.: Emerging Value Propositions for M-commerce. Journal of Business Strategies 18(2), 133-148 (2001)

7. De Reuver, M., Bouwman, H., Kaaker, T.: Mobile Business Models: Organizational and Financial Design Issues That Matter. Electronic Markets 19(1), 3-13 (2009)

8. Germanakos, et al.: Improving M-Commerce Services Effectiveness with the Use of UserCentric Content Delivery. Journal of Electronic Commerce in Organizations 6(1), 1-18 (2008)

9. Grimsley, M., Meehan, A.: E-government Information Systems: Evaluation-led Design for Public Value and Client Trust. European Journal of Information Systems 16(2), 134-148 (2007)

10. Hoehle, H., Scornavacca, E.: Unveiling Experts Perceptions Towards the Characteristics and Value Proposition of Mobile Information Systems. In: Proceedings of the 7th International Conference on Mobile Business (ICMB 2008), pp. 334-343 (2008)

11. Hossain, M.D., Moon, J., Kim, J.K., Choe, Y.C.: Impacts of Organizational Assimilation of e-Government Systems on Business Value Creation: A Structuration Theory Approach. Electronic Commerce Research and Applications 10(5), 576-594 (2011)

12. Hu, P.J.H., et al.: Law Enforcement Officers' Acceptance of Advanced E-government Technology: A Survey Study of COPLINK Mobile. Electronic Commerce Research and Applications 10(1), 6-16 (2011)

13. Janssen, M., Kuk, G.: E-government Business Models for Public Service Networks. International Journal of Electronic Government Research 3(3), 54-71 (2007)

14. McAdam, R., Walker, T.: An Inquiry into Balanced Scorecards within Best Value Implementation in UK Local Government. Public Administration 81(4), 873-892 (2003)

15. Monares, A., et al.: Mobile Computing in Urban Emergency Situations: Improving the Support to Firefighters in the Field. Expert Systems with Applications 38(2), 1255-1267 (2011)

16. Nah, F.F.H., Siau, K., Sheng, H.: The Value of Mobile Applications: A Utility Company Study. Communications of the ACM 48(2), 85-90 (2005)

17. Ntalinai, M., Costopoulou, C., Karetsos, S.: Mobile Government: A Challenge for Agriculture. Government Information Quarterly 25(4), 699-716 (2008)

18. Panagiotopoulos, P., Al-Debei, M.M., Fitzgerald, G., Elliman, T.: A Business Model Perspective for ICTs in Public Engagement. Government Information Quarterly 29(2), 191-202 (2012)

19. Prakash, N., Jaiswal, M., Gulla, U.: A Conceptual Framework for Measuring Public Value of Enterprise Applications. Electronic Government: An International Journal 6(3), 307-326 (2009)

20. Renegar, B.D., Michael, K., Michael, M.G.: Privacy, Value and Control Issues in Four Mobile Business Applications. Proceedings of the 7th International Conference on Mobile Business (ICMB 2008), pp. 30-40 (2008)

21. Schubert, P., Hampe, J.F.: Mobile Communities: How Viable are Their Business Models? An Exemplary Investigation of the Leisure Industry. Electronic Commerce Research 6(1), 103-121 (2006)

22. Sgriccia, M., et al.: Drivers of Mobile Business Models: Lessons from Four Asian Countries. International Journal of Mobile Computing 2(2), 58-67 (2007)

23. Teece, D.J.: Business Models, Business Strategies and Innovation. Long Range Planning (2009) (article in press)

24. Trimi, S., Sheng, H.: Emerging Trends in M-government. Communications of the ACM 51(5), 53-58 (2008) 
25. Varshney, U.: Business Models for Mobile Commerce Services: Requirements, Design, and the Future. IT Professional 10(6), 48-55 (2008)

26. Vincent, J., Harris, L.: Effective Use of Mobile Communications in E-Government. Information, Communication \& Society 11(3), 395-413 (2008)

27. Yan, P., Zhang, X., Zhang, Y.: The Value Analysis of Mobile Government. In: Qu, X., Yang, Y. (eds.) IBI 2011, Part I. CCIS, vol. 267, pp. 180-186. Springer, Heidelberg (2012)

28. Yu, C.C.: Building a Value-Centric e-Government Service Framework Based on a Business Model Perspective. In: Wimmer, M.A., Scholl, H.J., Ferro, E. (eds.) EGOV 2008. LNCS, vol. 5184, pp. 160-171. Springer, Heidelberg (2008) 